University of Nebraska - Lincoln

DigitalCommons@University of Nebraska - Lincoln

9-1-1999

\title{
High Energy Products in Exchange-Coupled Nanocomposite Films
}

\author{
J. Ping Liu \\ University of Nebraska-Lincoln, pliu@uta.edu \\ Yi Liu \\ University of Nebraska-Lincoln, yliu@unl.edu \\ Ralph Skomski \\ University of Nebraska-Lincoln, rskomski2@unl.edu \\ David J. Sellmyer \\ University of Nebraska-Lincoln, dsellmyer@unl.edu
}

Follow this and additional works at: https://digitalcommons.unl.edu/physicssellmyer

Part of the Physics Commons

Liu, J. Ping; Liu, Yi; Skomski, Ralph; and Sellmyer, David J., "High Energy Products in Exchange-Coupled Nanocomposite Films" (1999). David Sellmyer Publications. 70.

https://digitalcommons.unl.edu/physicssellmyer/70

This Article is brought to you for free and open access by the Research Papers in Physics and Astronomy at DigitalCommons@University of Nebraska - Lincoln. It has been accepted for inclusion in David Sellmyer Publications by an authorized administrator of DigitalCommons@University of Nebraska - Lincoln. 


\title{
High Energy Products in Exchange-Coupled Nanocomposite Films
}

\author{
J.P. Liu, Y. Liu, R. Skomski, and D.J. Sellmyer \\ Center for Materials Research and Analysis, \\ University of Nebraska, Lincoln, NE 68588-0113, U.S.A.
}

\begin{abstract}
Several systems of nanocomposite thin films have been prepared by plasma sputtering and heat treatment. By choosing suitable multilayer structures of the as-deposited films and subsequent heat-treatment processes, the nanostructures of the films have been tailored. The thermal processing is the key to control the morphology. Appropriate heat-treatment processes have been found for the systems studied, which result in the desired nanostructures. For the first time a nearly ideal nanostructure with the soft-phase grains embedded homogeneously in the hard phase grains has been obtained for the FePt-Fe $e_{1-x} \mathrm{Pt}_{\mathrm{x}}(\mathrm{x} \sim 0.3)$ system. Effective intergrain exchange coupling has been realized. As a consequence, high energy products up to 50 MGOe have been achieved.
\end{abstract}

Index Terms-exchange coupling, heat treatment, permanent magnets, thin films.

\section{INTRODUCTION}

Since the discovery of experimental evidence for intergrain exchange coupling between magnetically hard phase and soft phase [1], many experimental investigations have been done with the purpose of obtaining higher energy products [2-6]: Theoretical works [7-10] have predicted very high energy products of the exchange-coupled nanocomposite magnets. However, experimental attempts by mechanical alloying and rapid quenching have resulted in energy products only up to about $20 \mathrm{MGOe}$. This is because these methods have the technical difficulty in controlling the nanostructures, especially the grain size and the texture.

This difficulty stimulated us to try to realize the ideal nanostructure and therefore better intergrain exchange coupling by preparing the nanocomposite materials by sputtering and subsequent heat treatment. In the past three years we have successfully prepared several model systems of the hard-soft phase nanocomposites with required homogenous nanostructures by plasma sputtering and heat treatments. The systems produced and studied include FePt$\mathrm{Fe}_{1-\mathrm{x}} \mathrm{Pt}_{\mathrm{x}}(\mathrm{x} \sim 0.3), \mathrm{PrCo}_{35^{-}} \mathrm{Co}$ and $\mathrm{SmCo}_{\mathrm{x}} \mathrm{Co}(\mathrm{x}=3,3.5,4,5$ and 8) (we use the notations like PrCo-Co to represent the composites after annealing and the notations like $\mathrm{PrCo} / \mathrm{Co}$ to represent the as-deposited multilayers). In this paper we will present selected experimental results that illustrate theoretical concepts and experimental challenge in designing excellent exchange-coupled permanent magnets.

Manuscript received February 28, 1999.

J. P. Liu, 402-472-2682, fax 402-472-2879, pliu@unlinfo.unl.edu.

Research supported by the AFOSR (F49620-98-1-0098), J.P.L., R.S. and D.J.S. are also supported in part by the US DOE (DE-F6-0286ER45262), DAPPA through ARO (DAAG-55-98-1-0268), and NSF (INT9812082).

\section{EXPERIMENT}

The production of the nanocomposite films started with the deposition of multilayers in a multiple-gun DC- and RFplasma sputtering system. Targets were commercial products or homemade by sintering powdered materials. Purities of all the target materials were higher than 99.9 at.\%. Glass or silicon substrates were used in this investigation. The substrates were attached to a rotating table that was cooled by water during sputtering. The base pressure in the chamber was $2 \times 10^{-7}$ Torr. Flowing high-purity argon gas was used for sputtering and the pressures were varied from 5 to 30 mTorr. For the $\mathrm{PrCo}_{3.5}$-Co and $\mathrm{SmCo}_{\mathrm{x}}$-Co $(\mathrm{x}=3,3.5,4,5$ and 8) systems, Cr underlayers with thickness from 50 to $70 \mathrm{~nm}$ and coverlayers with thickness $10 \mathrm{~nm}$ were deposited.

The sputtering parameters in this investigation (including the argon pressure, the power rates of sputtering guns and the targets-to-substrate distance) were chosen to produce films with maximum coercivity. The thickness of each film was calculated by measuring the mass gain upon deposition and by low-angle X-ray diffraction.

The as-deposited films were then heat treated in various processes including rapid thermal annealing (RTA). In this process, heating and cooling rates up to $100 \mathrm{~K} / \mathrm{s}$ were employed. Details of the preparation conditions can be found in our previous publications [11-15].

Magnetization loops were measured by an alternating gradient force magnetometer (AGFM) and a superconducting quantum interference device (SQUID) magnetometer. Nanostructure of the films was observed by a transmission electronic microscope (TEM). X-ray diffraction (XRD) and energy dispersive $\mathrm{x}$-ray spectroscopy (EDX) have been used to identify the phase structures of the sample. Magnetic force microscopy (MFM) and atomic force microscopy (AFM) were used to observe the domain structures and the surface morphology.

\section{RESULTS AND DISCUSSION}

\section{A. Magnetic Hardening in the Nanocomposites}

The as-deposited films generally behaved like soft magnetic materials except for $\mathrm{SmCo}_{3,5} / \mathrm{Co}$ in which coercivity up to $1 \mathrm{kOe}$ was measured after the deposition. The soft magnetic behavior for $\mathrm{PrCo}_{3.5} / \mathrm{Co}$ multilayers can be attributed to the fact that the as-deposited films have antorphous structure. For the iron-platinum system, the multilayers were deposited by sputtering alternatively the $\mathrm{Fe}$ layers and the $\mathrm{Pt}$ layers onto the substrates at room temperature. Subsequent heat treatment was necessary to form the magnetically hard phase, the equal-atomic $\mathrm{Ll}_{0}$ (fct) FePt phase. 
Magnetic hardening was realized upon annealing for all the systems under investigation. By choosing carefully the annealing time and temperature, coercivity up to $20 \mathrm{kOe}$ in the $\mathrm{FePt}-\mathrm{Fe}_{\mathrm{x}} \mathrm{Pt}_{1 \mathrm{x} x}(\mathrm{x} \sim 0.7)$ and $\mathrm{PrCo}_{3.5} \mathrm{Co}$ systems was developed $[11,13]$. In $\mathrm{SmCo}_{\mathrm{x}}-\mathrm{Co}$ systems, huge coercivity ( $>40 \mathrm{kOe}$ ) has been obtained [15].

As reported by other groups, there is a trade-off between the magnetization and coercivity in the hard-soft-phase composites. We also observed this phenomenon. Figure 1 shows $\mathrm{H}_{c}$ and $\mathrm{M}_{s}$ measured as functions of the Co layer thickness in the $\mathrm{PrCO}_{3.5} \mathrm{Co}$ system.

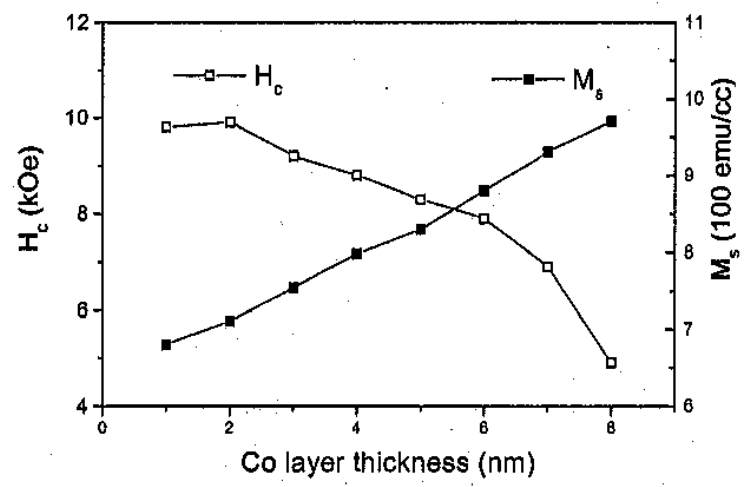

Fig. 1. Dependencies of coercivity and the saturation on Co layer thickness in the film $(\mathrm{PrCo} 28 \mathrm{~nm} / \mathrm{Co} \mathrm{nm}) \times 8$ (annealed at $500^{\circ} \mathrm{C}$ ).

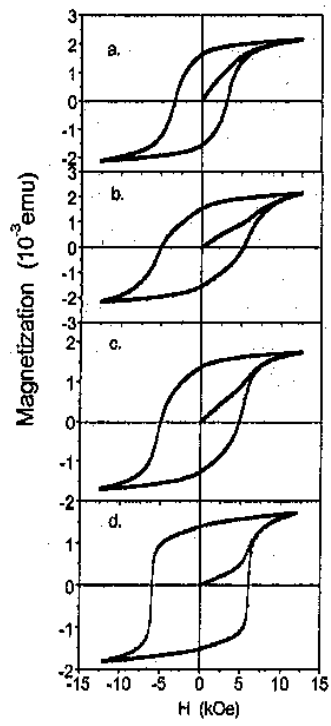

Fig.2. Hysteresis loops of the heat treated multilyers with structure $(\operatorname{PrCo} 30 \mathrm{~nm} / \mathrm{Cox} \mathrm{nm}) \times 10$. In figure $\mathrm{a}, \mathrm{x}=11 \mathrm{~nm}$, in $\mathrm{b}, \mathrm{x}=10 \mathrm{~nm}$, $c, x=8 \mathrm{~nm}$ and in $\mathrm{d}, \mathrm{x}=5 \mathrm{~nm}$. The magnetization was measured with the field in the film plane.

It is noteworthy that we have found that there is a correlation between the coercivity mechanism and the soft phase fraction in the composite. Figure 2 shows the initial magnetization curves and the hysteresis loops of the $\mathrm{PrCo}_{3.5}$ $\mathrm{Co}$ samples with different $\mathrm{Co}$ fractions. A commonly accepted interpretation of the initial curves (virgin curves) is that steep curves, as for sample (a), indicate a nucleation-type mechanism of coercivity; whereas curves as for sample $d$, are typical for wall-pinning controlled reversal. That may be because softer phase in the composite provides more nucleation sites for the reversed domains. However, in case of nanoscale morphology, one may need to consider interaction domains [16,17], because simple nucleation and pinning models may not be completely adequate for describing the coercivity mechanism in nanocomposite magnets. As we can see from Fig. 3, the domain size ( 200 $\mathrm{nm})$ is about ten times bigger than the grain size $(\sim 20 \mathrm{~nm})$. This is a common phenomenon in all the systems investigated. A study of the details of the coercivity mechanism is underway. Though not yet fully understood, it can be still concluded from Fig. 2 that the Co phase fraction in the annealed samples has changed the magnetizationreversal processes.

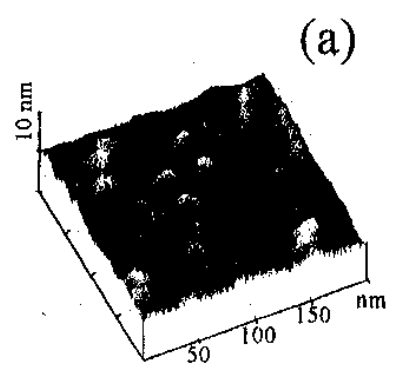

(b)

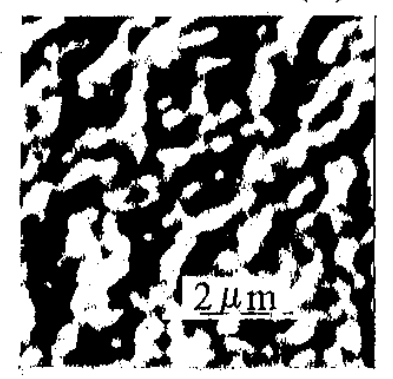

Fig. 3 The AFM (a) and MFM (b) images of a ( $\mathrm{PrCo} 30 \mathrm{~nm} / \mathrm{Co} 11 \mathrm{~nm}) \times 10$ sample with heat treatment at $500^{\circ} \mathrm{C}$.

\section{B. Nanostructure Analysis}

It is not difficult to understand that there are only three possible two-dimensional morphological configurations for a homogenous two-phase composite, as shown schematically in Fig. 4.

Skomski and Coey [8] have shown that to reach effective exchange coupling, the dimension of the soft phase should not be bigger than twice the domain-wall thickness of the hard phases. By "dimension" here we mean either the grain size in case Fig. 4 (b) or the shortest distance between two 
adjacent grains which are embedded in the matrix phases, in case (a) or (c). Though theoretical calculations did not give a topological limitation to the hard phase, the dimension of the hard phase also should be small in order to increase the fraction of the soft phase to raise the remanent magnetization.

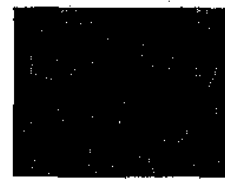

(a)

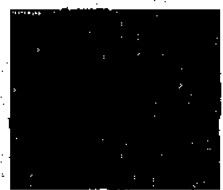

(b)

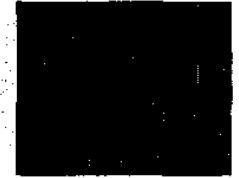

(c)
Fig. 4 Three possible two-dimensional configurations of a two-phase composite. (a) the light phase embedded in the dark phase; (b) two phases with comparable grain size; (c) the dark phase embedded in the light phase

Another important point is that, in order to create a texture in the composite which is of vital importance for a permanent magnet, a configuration with small soft-phase grains distributed homogeneously in the hard phase is ideal. Though the reversed picture was first suggested in Ref. [7], our experimental results and theoretical consideration have proved that a composite with soft-phase matrix will not work as good as the reversed configuration. The reason is that only in the case that soft-phase grains are distributed in hard-phase matrix, can significant magnetic anisotropy and high coercivity of the composite be achieved. If we had the reversed situation, i.e., small hard-phase grains are distributed in the matrix of the soft phase, it would be very hard to align all the small hard-phase grains. Exceptional situation may happen when perfect grain-boundary coherence exists between the hard and soft phases and the crystalline orientation of all hard phase grains is same. Even in this perfect case, it would also be very difficult to ensure that the dimension of the soft phase is under the critical length for effective intergrain exchange coupling. The juxtaposition of grains of soft phases to hard-phase grains is also guaranteed when the soft-phase grains are embedded in the hard matrix. This is also essential for the intergrain exchange coupling.

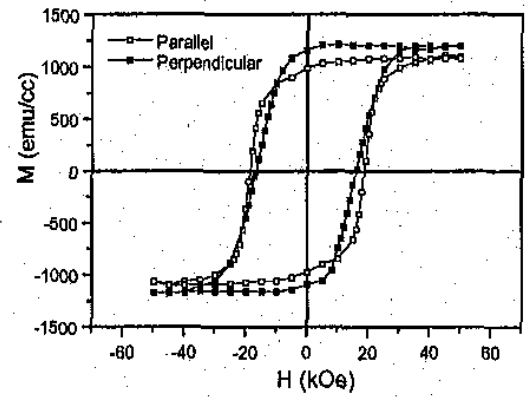

Fig.5. Hysteresis loops of the annealed (Fe $2.1 \mathrm{~nm} / \mathrm{Pt} 1.5 \mathrm{~nm}) \times 16$ sample measured in different directions. Plotted on the abscissa is the applied field.
Here we can answer the question regarding why high energy products have not yet been achieved in mechanically alloyed and melt-spun composites. The reasons may be among the following: (1) The grain size was not small enough (smallest size reported thus far was still bigger than the critical length); (2) The grains of the two phases did not contact each other sufficiently (distribution was not homogenous enough); (3) all the samples were magnetically isotropic (no texture was achieved).
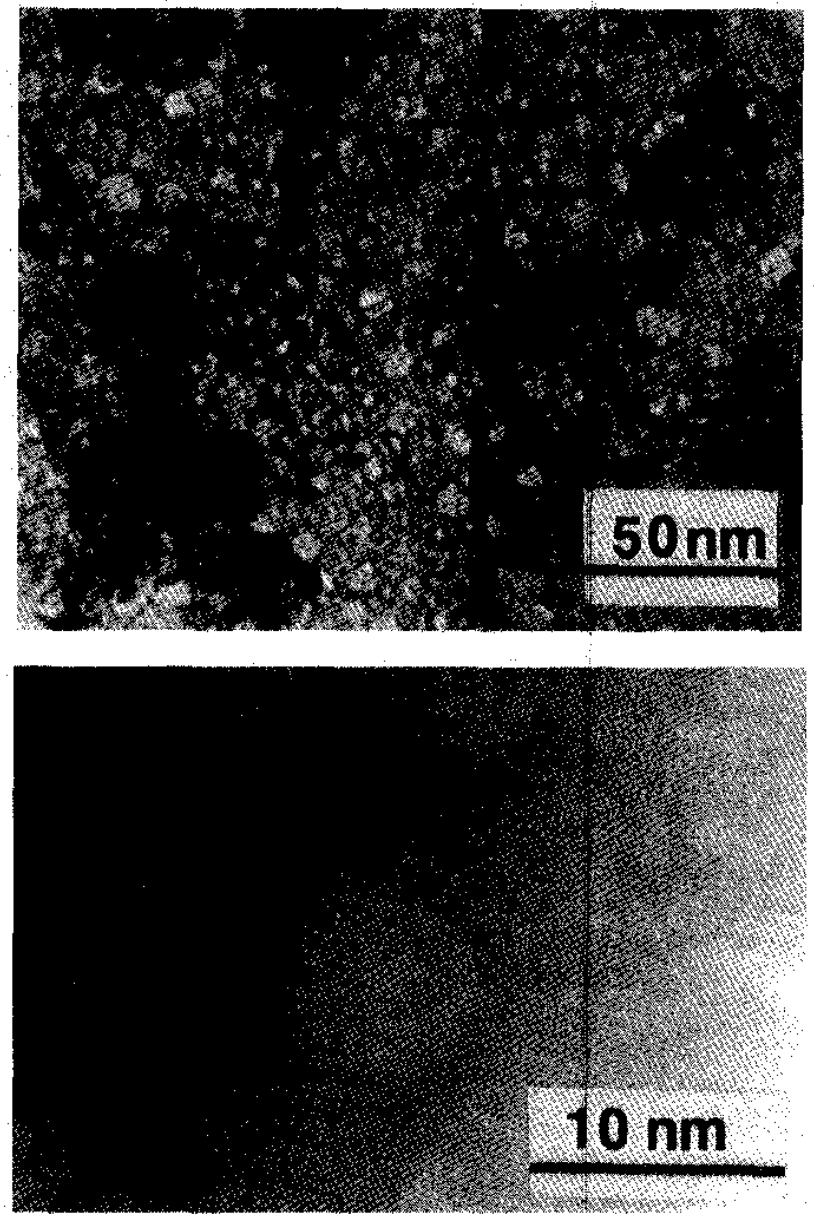

Fig. 6 TEM bright-field image (upper part) and high resolution TEM image (lower part) of a heat treated sample. The "white grains" with diameter less than $10 \mathrm{~mm}$ are fcc phase which are embedded in the FePt matrix grains with lateral grain size from 50 to $100 \mathrm{~nm}$.

These problems have been solved in our experiment on the $F e P t-F e_{1-x} P t_{x}(x \sim 0.3)$ system. Figure 6 shows the nanostructure of a sample with energy product $52.8 \mathrm{MGOe}$. The hysteresis loops are shown in Fig. 5. Very small grain size of the fcc soft phase in the range from $5-8 \mathrm{~nm}$ was obtained after the RTA treatment. The EDX spectroscopy has shown that the composition of this fcc phase was $\mathrm{Fe}_{1-\mathrm{x}} \mathrm{Pt}_{\mathrm{x}}$ ( $\mathrm{x} \sim$ 0.3 ) that is close to the $\mathrm{Fe}_{3} \mathrm{Pt}$ phase. In the tetragonal $\mathrm{FePt}$ 
phase, the wall thickness is about $4 \mathrm{~nm}$ [18], which means that the grain size of the soft phase in the exchange-coupled FePt system should be smaller than $8 \mathrm{~nm}$. The fine soft-phase grains were embedded in the matrix of the fct hard phase with grain size in the range of 50-100 $\mathrm{nm}$. The hard-phase grains were connected to each other all over the sample, which made it possible for an out-of-plane anisotropy. We noticed that in single phase FePt films, the as-deposited films had (111) texture (with $\langle 111\rangle$ normal to the film plane). If annealing temperature was higher than $500^{\circ} \mathrm{C}$, the orientation became (001), i.e. perpendicular anisotropy (easy magnetization direction of the fct phase is $\langle 001\rangle)$. In the case of the nanocomposite, the situation was more complicated and determination of the texture was more difficult. However, we observed similar change in anisotropy from in-plane to out-of-plane with increasing annealing temperature. Therefore it is clear that the out-of-plane anisotropy was not caused by the film growth preference but was developed after sufficient annealing. If the hard phase were not connected all over the sample, the texture hardly could have been achieved, as we discussed above.

In the $\mathrm{PrCo}_{\mathrm{x}}$-Co and $\mathrm{SmCo}_{\mathrm{x}}-\mathrm{Co}$, nanostructures with the type shown in Fig. 4(b) were obtained. When the soft-phase portion in the composites was small (resulting from the thin Co layers in the multilayers), the grain size of the soft phase was naturally smaller than the hard-phase grains. However, different from the iron-platinum samples, Co grains were found only in the grain boundaries. Because the grain size was well controlled, energy products above 20 MGOe were achieved [12,15]. These two systems showed in-plane anisotropy (in the film plane), which may be related to the grain orientation formed during film growth. For $\mathrm{PrCo}_{x}$-Co samples, the as-deposited films were amorphous. The crystalline planes were formed during the subsequent heat treatment. Detailed investigation on the anisotropy of the samarium- cobalt and praseodymium-cobalt is underway.

\section{Intergrain Exchange Coupling}
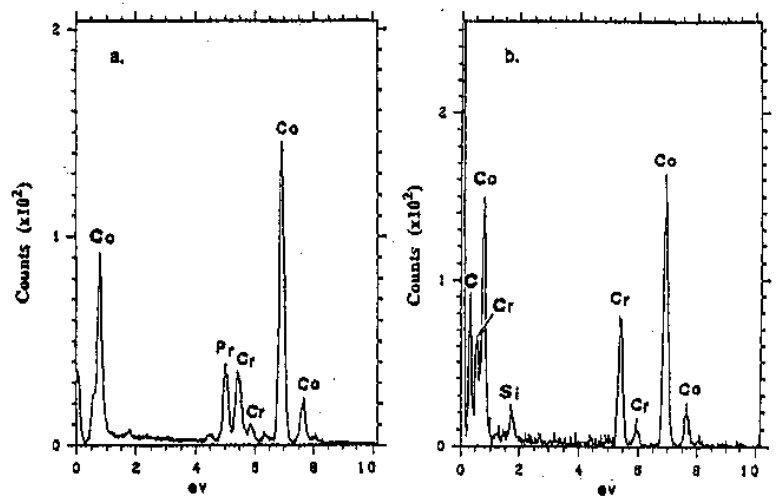

Fig. 7. EDX spectra of a heat treated $\mathrm{PrCO}_{x}$-Co film. (a) from the matrix grain and (b) from the second phase grain.
XRD, TEM and EDX have been used to identify the crystal structures of the phases in the nanocomposites studied. In the $\mathrm{PrCo}_{x}-\mathrm{Co}$ and $\mathrm{SmCo}_{x}$-Co systems, the hep Co phase was detected in the heat-treated samples. Figure 7 shows the EDX spectra of a $\mathrm{PrCo}_{\mathrm{x}}-\mathrm{Co}$ sample measured in two adjacent grains. One is the matrix grain (a) and another is the softphase grain (b). Except for $\mathrm{Cr}$ peaks that are from the cover layer and under layer, and a trace of $\mathrm{Si}$ and $\mathrm{C}$ which may be from the substrate and the contamination during the specimen preparation, in (a) we detected Co and Pr elements, and in (b) we only detected Co. This shows clearly that there are two phases, the hard $\mathrm{PrCo}_{x}$ phase and soft Co phase existing in the composite. No third phase was found.

Crystal structures of the hard phases in $\mathrm{PrCo}_{\mathrm{x}}$-Co and $\mathrm{SmCo}_{\mathrm{x}}-\mathrm{Co}$ systems were found to be different from those in bulk samples $[12,15]$. In the $\mathrm{SmCo}_{3.5}$-Co system, highresolution TEM showed the hard phase to be a metastable phase $\mathrm{SmCo}_{3}$ with the hexagonal $\mathrm{DO}_{19}$ structure. The reason remains to be explored.

In the iron-platinum system, unexpectedly, no pure iron phase was found but the $\mathrm{fcc} F e_{1-x} \mathrm{Pt}_{\mathrm{x}}$ with $\mathrm{x} \sim 0.3$, as mentioned above.

The simplest way to see if there is an intergrain exchange coupling in a composite sample is through the hysteresis loops. The ratio of the remanence and the saturation $\left(\mathrm{M}_{\mathrm{r}} / \mathrm{M}_{\mathrm{s}}\right)$ higher than 0.5 is a sign of exchange coupling.

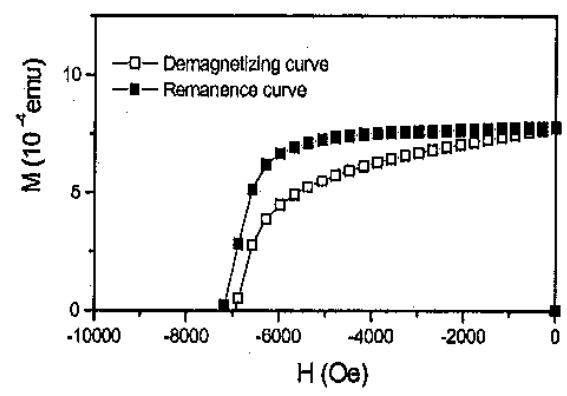

Fig. 8. The demagnetizing curve and the remanence curve of an annealed sample (PrCo $30 \mathrm{~nm} / \mathrm{Co} 8 \mathrm{~nm}) \times 10$.

Another way is to measure the "exchange spring" behavior. We measured the $M_{R}$ vs. $H$ (magnetic field) curves. Here $M_{R}$ is different from the remanent magnetization $M_{r} \cdot M_{r}$ is only one value at $\mathrm{H}=0$ when external magnetic field decreases from the first quadrant. $\mathrm{M}_{R}$ can have different values at $\mathrm{H}=0$ when opposite fields release from different points in the second quadrant. Figure 8 shows an example. When the $M_{R}$ vs. $H$ curve is flat, it indicates that $M_{R}$ does not change, which means that the moment of the soft phase switched back after the external field vanished.

These measurements should of course be combined with the nanostructure observations discussed above. It has been found in our experiments that when the soft-phase grain size extensively exceeded the critical length, the exchange 
coupling failed, showing in the loops with pronounced kinks (shoulders) around $\mathrm{H}=0$, which indicates that the soft phases did not switch together with the hard phases.

A multi-step heat treatment has been adopted to improve the situation. Figure 9 shows the loops of the $\mathrm{SmCo}_{\mathrm{x}}-\mathrm{Co}$ sample treated with different procedures: (a) RTA at $500^{\circ} \mathrm{C}$ for 20 seconds, (b) anneal at $500^{\circ} \mathrm{C}$ for 20 minutes, and (c) a combination of (a) plus (b).

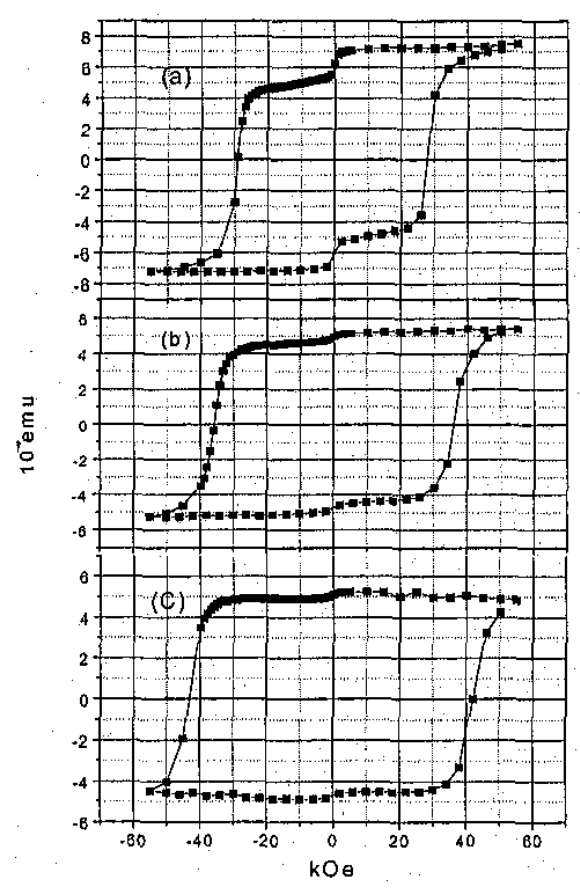

Fig. 9 The SmCo films treated with different processes.

(a) $500^{\circ} \mathrm{C}$ RTA; (b) $500^{\circ} \mathrm{C} 20 \mathrm{~min}$. anneal and (c) treatment

(a) plus (b).

It can be seen clearly from Fig.9 that the two-step treatment led to the most effective intergrain exchange coupling (with smallest kinks on the loop). Loop (c) is only a minor loop because our measurement field could only be applied up to $55 \mathrm{kOe}$. If we can measure this sample to higher field, the difference between loop (c) and (b) will be more obvious. It turned out in our experiments that no single-step treatment could lead to as good result as the two-step one, This is because if the as-deposited sample were treated with standard annealing directly, it could cause excessive grain growth. This would destroy the intergrain exchange coupling. However, sufficient annealing was necessary for high coercivity. To solve this dilemma, a special rapid thermal annealing process was first applied to the samples. In this process, annealing at above $500^{\circ} \mathrm{C}$ can be done in 5 seconds; the heating rate can be about $200^{\circ} \mathrm{C}$ per second.

We applied this two-step treatment to all the systems under investigation. It gave good results for most samples.
Other multi-step treatments were also tested, giving even better results. A detailed study is still underway.

Another effect on the exchange coupling is the grain boundary conditions. In view of metallurgical processes, more sufficient annealing leads to "cleaner" grain boundaries. By "cleaner" we mean less defects, less distortion and more coherent. As we have seen, this change helps the intergrain exchange coupling. The influence of grain-boundary coherence can be also seen from the effect of additional elements in the soft phases. When Co was added to the FePt$\mathrm{Fe}_{1-\mathrm{x}} \mathrm{Pt}_{\mathrm{x}}$ samples, the coercivity dropped. Similar situation was found when $\mathrm{Fe}$ was added to the $\mathrm{PrCo}_{\mathrm{x}}-\mathrm{Co}$ and $\mathrm{SmCo}_{\mathrm{x}}-\mathrm{Co}$ systems. We speculate that the additions have degraded the grain-boundary coherence. The above experimental observations are consistent with our recent theoretical studies $[19,20]$.

\section{SUMMARY}

By sputtering and proper heat treatment, $\mathrm{FePt}-\mathrm{Fe}_{1-x} \mathrm{Pt}_{x}$, $\mathrm{PrCO}_{\mathrm{x}}-\mathrm{Co}$ and $\mathrm{SmCo}_{\mathrm{x}}-\mathrm{Co}$ composite films with high energy product up to $50 \mathrm{MGOe}$ have been successfully produced. For the first time we obtained a nearly ideal nanostructure of the composite $\mathrm{FePt}-\mathrm{Fe}_{1-x} \mathrm{Pt}_{\mathrm{x}}$, with the soft-phase grains under the critical size homogeneously embedded in the matrix of the hard phase. This turns out to be the best nanostructure type for effective intergrain exchange coupling. The intergrain exchange coupling has also been observed in the nanostructures of the systems $\mathrm{PrCo}_{\mathrm{x}}-\mathrm{Co}$ and $\mathrm{SmCo}_{\mathrm{x}}-\mathrm{Co}$ in which the grain size was well controlled. It has been suggested that the grain boundary conditions play an important role in the exchange coupling.

\section{ACKNOWLEDGEMENT}

J. P. L is grateful to Profs. S. Jaswal, Z.S. Shan, D. L. Leslie-Pelecky and Mr. C.P. Luo for many fruitful discussions. The AFM and MFM observations were performed with help from Prof. S.H. Liou.

\section{REFERENCES}

[1] R. Coehoorn, D.B. de Mooij and C. de Waard, "Meltspun permanent magnet materials containing $\mathrm{Fe}_{3} \mathrm{~B}$ as the main phase," J. Magn. \& Magn. Mater, Vol. 80, pp.101-104, 1989.

[2] P. G. McCormick, W.F. Miao, P.A.I. Smith, J. Ding and R. Street, "Mechanically alloyed nanocomposite magnets," J. Appl. Phys., Vol. 83 , pp. 6256-6261, June 1998.

[3] E.E. Fullerton, J.S. Jiang, C.H. Sowers, J.E. Pearson, and S.D. Bader, " Structure and magnetic properties of exchange-spring $\mathrm{Sm}-\mathrm{Co} / \mathrm{Co}$ superlattices," Appl. Phys. Lett. Vol. 72, pp. 380-382, January 1998.

[4] D.H. Ping, K. Hono and S. Hirosawa, "Partition of $\mathrm{Ga}$ and Co atoms in a $\mathrm{Fe}_{3} \mathrm{~B} / \mathrm{Nd}_{2} \mathrm{Fe}_{14} \mathrm{~B}$ nanocomposite magnet", $J$. Appl. Phys, , 83, pp77697775, June 1998. 
[5] Youhui Gao, Jinghan Zhu, Yuqing Weng, Eon Byung Park, Choong Jin Yang, "The enhanced exchange coupling interaction in nanocrystalline $\mathrm{Nd}_{2} \mathrm{Fe}_{14} \mathrm{~B}+\alpha \mathrm{Fe}$ alloys with improved microstructure", J. Magn. \& Magn. Mater., 191 pp. 146-152, 1999.

[6] J. Jakubowicz, A. Szlaferek, M. Jurczyk, "Magnetic properties of nanostructured $\mathrm{Nd}_{2}(\mathrm{Fe}, \mathrm{CoCr})_{14} \mathrm{~B} / \alpha-\mathrm{Fe}$ magnets", $J$. Aloys and Compounds, 283, pp. 307-310, 1999.

[7] Eckart F, Kneller and Reinhard Hawig, "The exchange-spring magnet: a new materialprinciple for permanent magnets", IEEE Trans. on Magnetics, 27, 3588, 1991.

[8] Ralph Skomski and J.M.D. Coey, "Giant energy product in nanostructured two-phase magnets," Physical Review B, Vol. 48, pp. 15812-15816, December 1993.

[9] R.F. Sabiryanov, S.S. Jaswal, "Electronic structure and magnetic properties of hard/soft multilayers," J. Magn. \& Magn. Mater., 177. 181 pp. 989-990, 1998.

[10] R.F. Sabiryanov, S.S. Jaswal, "Magnetic properties of hard/soft composites: $\mathrm{SmCo}_{5} / \mathrm{Co}_{1-\mathrm{x}} \mathrm{Fe}_{\mathrm{x}}$," Physical Review B, 58, pp. 12071 12074, November 1998.

[11] J.P. Liu, Y. Liu, C.P. Luo, Z.S. Shan and D.J. Sellmyer, "Magnetic hardening in FePt/Fe nanostructured films", J. Appl. Phys,, Vol. 81, pp. 5644-5646, 1997.

[12] J.P. Liu, Y. Liu, Z.S. Shan and D.J. Sellmyer, "Remanence enhancement and exchange coupling in $\mathrm{PrCo} / \mathrm{Co}$ films", IEEE Trans. on Magn, 33, pp. 3709-3711, 1997.

[13] J.P. Liu, Y.Liu and D.J. Sellmyer, "Coercivity and exchange coupling in PrCo:Co nanocomposite film," J. Appl. Phys., Vol, 83, pp. 6608$6610,1998$.

[14] J.P. Liu, C.P. Luo, Y.Liu and D.J. Sellmyer, "High energy products in rapidly annealed nanoscale $\mathrm{Fe} / \mathrm{Pt}$ multilayers", Applied Physics Letters, Vol. 72, pp. 483-485, January 1998.

[15] J.P. Liu, Y. Liu, R. Skomski and D.J. Sellmyer, "Magnetic hardening in $\mathrm{SmCo}_{\mathrm{x}}$-Co multilayers and nanocomposites", J, Appl. Phys., Vol.85, pp. 4812-4814, April 1999.

[16] W. Rave, D. Eckert, R. Schäfer, B. Gebel and K.-H. Müller, "Interaction domain in isotropic, fine-grained $\mathrm{Sm}_{2} \mathrm{Fe}_{17} \mathrm{~N}_{3}$ permanent magnets," IEEE Trans, Magnetics, Vol. 32, pp. 4362-3464, September 1996.

(17) R.K. Mishra, R.W. Lee, "Microstructure, domain walls, and magnetization reversal in hot-pressed Nd-Fe-B magnets," Appl. Phys. Lett., Vol. 48, pp. 733-735, March 1986.

[18]. T. Klemmer, D. Hoydick, H. Okumura, B. Zhang and W.A. Soffa, "Magnetic hardening and coercivity mechanisms in $\mathrm{Ll}_{0}$ ordered $\mathrm{FePd}$ ferromagnets," Scripta Metallurgica et Materialia, Vol. 33, pp. 17931805, December 1995.

[19] R. Skomski, J.P. Liu, M. Meldrim and D.J. Sellmyer, "Intergranular exchange in magnetic nanostructures," Proceeding of the tenth international symposium on magnetic anisotropy and coercivity in rare-earth transition-metal alloys, L. Schultz and K.-H.Muller, Eds. Dresden, pp. 277-286, September 1998.

[20] R. Skomski et al., "Effect of imperfect grain boundaries on the exchange coupling," in preparation. 